\title{
Decision-making in international business
}

Article

Accepted Version

Buckley, P. and Casson, M. (2019) Decision-making in international business. Journal of International Business Studies, 50 (8). pp. 1424-1439. ISSN 1478-6990 doi: https://doi.org/10.1057/s41267-019-00244-6 Available at https://centaur.reading.ac.uk/83283/

It is advisable to refer to the publisher's version if you intend to cite from the work. See Guidance on citing.

To link to this article DOI: http://dx.doi.org/10.1057/s41267-019-00244-6

Publisher: Palgrave Macmillan

All outputs in CentAUR are protected by Intellectual Property Rights law, including copyright law. Copyright and IPR is retained by the creators or other copyright holders. Terms and conditions for use of this material are defined in the End User Agreement.

\section{www.reading.ac.uk/centaur}

\section{CentAUR}

Central Archive at the University of Reading

Reading's research outputs online 
Decision Making in International Business

Peter Buckley and Mark Casson

Peter Buckley, Centre for International Business, University of Leeds, Moorland Road Leeds, LS6 1AN UK, Tel: (44) 113812 3190, E-mail@ pjb@lubs.leeds.ac.uk

Mark Casson, Department of Economics and Henley Business School, University of Reading, Reading R6 6AH, UK, Tel: (44) 118987 5123, E-mail: m.c.casson@ reading.ac.uk

Keywords: INTERNALISATION; INTERNATIONAL BUSINESS; MULTINATIONAL ENTERPRISE; DECISION-MAKING; ORGANISATION; RATIONALITY

Acknowledgements: The authors are grateful to the editors of the special issue for their comments on previous drafts 


\begin{abstract}
This paper builds on the preceding papers. It distinguishes three domains of international business theory: the boundaries of the multinational enterprise, the external environment of the enterprise and its internal structure. The central concern of internalisation theory is the boundaries of the firm. Any general theory of international business must analyse the external environment and internal structure as well. Competition dominates the external environment whilst co-operation dominates internal structure. Different models of decision-making are required for each. Different theories of decisionmaking must therefore be integrated in order to transform internalisation theory into a general theory of international business. This paper examines how this can be done.
\end{abstract}




\section{INTRODUCTION}

This paper has three main objectives: to critically review the current state of internalisation theory; to comment on the previous papers; and to outline a research agenda based on key theoretical issues. This agenda emerges partly from our own personal reflections, and partly from our reading of the special issue papers.

In the 1970s international business (IB) scholars were optimistic about the development of their field. IB scholarship attracted significant interest from other disciplines, including economics, politics, sociology, psychology, geography, history and statistics. In the past twenty years, however, the subject seems to have lost self-confidence. It now tends to follow intellectual trends in other fields rather than setting trends itself.

This paper considers the potential for reversing this situation in order to regain some of the intellectual ground that IB has surrendered. Instead of looking outwards from where IB studies is today, it look inwards on IB studies from where other disciplines are today, to see what there is that may interest them (Buckley and Casson, 2019). It concludes with some practical suggestions for developing new theory and re-engaging with these disciplines.

\section{THE SCOPE OF INTERNALISATION THEORY}

When internalisation theory was first developed in the 1970s, there were two main strands of IB research. One focused on the external environment of the firm, and was dominated by quantitative economic research, while the other focused on the key functional areas of management within the firm, such as marketing, procurement, accounting and finance. There was a degree of tension between these approaches. One reason for the difference was disciplinary: the external environment was largely the province of economics and politics, while internal process and structure was largely the province of sociology, psychology and business studies (Stopford and Wells, 1972). For a time, however, these differences were submerged, but they have gradually re-emerged and have now become so prominent that they need to be addressed. 
In the early days of IB theory one issue dominated all others: namely the post-1945 rise of the multinational enterprise (MNE). Neither the internal approach to the firm nor the external approach had the answer. The answer was to look at the nature of the firm itself (Rugman and Verbeke, 2008). It was realised that a firm was not just a single plant; it could be multi-plant, like a retail chain store, for example, whose shops shared a brand-name, or multinational, like an automobile manufacturer with factories in different countries. There were various rationales for multi-plant operation. One was that plants shared access to some intangible asset monopolised by the firm, e.g. a proprietary technology or brand (Hymer, 1976). Other rationales were possible too: e.g. buying power exercised through centralised procurement or tax-avoidance through internal 'transfer pricing' (Buckley ad Casson, 1976).

Centralised resources could be shared in two main ways: internally, within a single firm, or externally, through a network of contracts with independent local firms. Internalisation theory asserted that the structure of the firm reflected efficient choice (Casson, 2014; Coase, 1937; Hennart, 1982). The boundaries of the firm were set at convenient points where arm's length contracts worked reasonably well. Where contracts would not work, activities were internalised within the same firm. There was a trade-off: internalisation of activities reduced the costs of making contracts, but could require the firm to operate in risky and unfamiliar environments. Only if the savings in contractual costs outweighed these additional risks would the 'internalisation' of branch-plant production be profitable.

Firms whose managers made efficient choices would survive and prosper, and those whose managers made inefficient choices would not. The theory identified key factors that governed efficient choices and therefore dictated observed outcomes. These factors included the strength of intellectual property rights, the political risks of foreign ownership, and the ability to hire trustworthy local managers with local knowledge. Weak intellectual property rights, low political risks and access to trustworthy local managers all favoured the MNE; by contrast, strong intellectual property rights, high political risk and a lack of trustworthy local managers all favoured licensing or franchising instead (Casson, 2016).

Economic geography was important too. High tariff and non-tariff barriers, and low costs of international knowledge transfer encouraged local production in foreign markets, while economics of 
scale in production encouraged the centralisation of production at a single export hub. High costs of international knowledge transfer encouraged location of the hub in the home country. The more that localised production was favoured, the more likely was the MNE to emerge. MNEs, in other words, emerged under certain conditions but not under others.

The interplay of proprietary knowledge, contractual costs and economic geography gave internalisation theory its unique capability to explain the MNE. But internalisation has never been just a theory of the MNE; it is essentially a general theory of the firm in space. It sets out the conditions under which related business activities will be brought under common ownership and control, and the conditions under which they will not. It is, therefore, not only a theory of why some firms are MNEs but also a theory about why many firms are not. Internalisation theory relates to the entire population of firms within an industry.

Internalisation theory therefore has a wider scope than IB theory. It explains the relationships between technology-owners and their foreign licensees, whether or not the technology owners and the licensees are MNEs. It explains the emergence of multi-regional firms, irrespective of whether they are multinational. Multinationality is often a political accident, resulting from the enlargement or partition of a country after war; e.g. the modern US borders with Canada and Mexico are both quite arbitrary from an economic point of view. Modern IB studies focuses on international boundaries to a singular degree. Even if there were no international boundaries, there would still be global businesses, global-value chains and multi-plant firms - but apparently IB studies would not study them because no national boundaries would be involved!

In other respects, however, IB studies transcends internalisation theory. IB theory claims to address any and all of the issues that arise with respect to MNEs. Some of these issues have little direct connection with internalisation theory; e.g. the adaptation of marketing strategies to domestic cultures, or the internal organisation of local procurement within a foreign subsidiary.

There are other issues, however, which are connected to internalisation, but which are not directly addressed by the theory in its current state of development. For example, the theory does not explain 
how many MNEs will dominate a global market, or the specific countries in which they will be headquartered. Internalisation is a necessary component of such explanations, but not a sufficient one. Neither does it explain the financial structure of the firm, e.g. the debt/equity ratio, or the internal organisational structure through which resources are allocated between subsidiaries. Once again, however, it is a necessary component of any such explanation.

To transform internalisation into a truly general theory of IB it is necessary to incorporate other theories within the framework. To address the issue of competition for global market share, for example, a theory of oligopolistic rivalry is required. To address the issue of debt versus equity a financial theory of risk-management is required, while to address the issue of organisational structure, a theory of decentralisation and delegation is required (Casson, 1995; Egelhoff, 1988, 1993).

This raises the issue as to whether the theory should be extended, or whether other theories should be developed alongside it instead. As a theory is extended it necessarily becomes complex, and therefore more difficult to understand. It may also lose coherence. Different elements introduced into the theory may be based on incompatible assumptions, so that theoretical diversity leads to loss of logical consistency.

The dangers of the process are illustrated by Dunning's 'eclectic theory' (Cantwell, 2003). The eclectic theory bundled together the three key elements of internalisation theory into a single accessible framework. In Dunning's terminology 'proprietary knowledge' became 'ownership advantage', contractual costs determined 'internalisation advantage' and economic geography governed 'location advantage'. Dunning reviewed the literature on each of these three advantages, and then included relevant ideas from this literature in his theory. But some of this literature was based on one set of assumptions, and some on another, and some on no clearly stated assumptions at all. To accommodate this diversity, the theory evolved into the OLI 'paradigm'. As a paradigm it gained in generality, and became a useful 'one stop shop' for new researchers in the field. But it was no longer a theory, because there was no longer any core set of assumptions from which all its propositions were derived (Eden, 2003). 
There is a danger that the same thing could happen again. An attempt to create a new theory of everything in IB could result in a new theory of nothing. It is a nice idea to make IB an 'inclusive subject' where any new theory is welcomed and added to the body of theoretical knowledge. But once the body of knowledge loses consistency, it also loses clarity. Internal contradictions emerge, and disputes arise as to how they should be resolved. New concepts are introduced to 'paper over the cracks'. Concepts proliferate, but no new insights are created as a result.

\section{THE VERSATILITY OF INTERNALISATION THEORY}

Another problem with extending internalisation theory is that the existing theory is not always properly understood. There are some issues that need to be clarified before the theory is developed further.

Internalisation theory sets out a menu of possible forms that multinationality can take. There is a basic distinction, made in the 1970s, between horizontal and vertical integration. Under horizontal integration the MNE owns different plants at the same stage of production, whereas with vertical integration it owns plants at different stages of production. According to Dunning, internalisation of technology and brands typically leads to 'market-seeking' investments by horizontally integrated firms, while internalisation of intermediate products, such as semi-processed commodities and manufactured components leads, respectively, to 'resource-seeking' and 'efficiency-seeking' investments by vertically integrated firms.

Different forms of ownership can also be distinguished. It is well-known, for example, that ownership of technology can be shared with a joint-venture partner, and that different types of agreement can be made between the partners regarding equity shares, governance structures, and buy-out options. It is less well-known that a firm can also own product without owning the plant in which the product is produced. In a global value chain, for example, the 'orchestrator' firm may own the product as it progresses through successive stages of production, even though it does not necessarily own the plants in which the product is processed. This arrangement was known in the nineteenth century as a 'putting out' system. The orchestrator may therefore own foreign assets, in the form of inventory and work in 
progress, even though it does not own any foreign plants (Casson, 2016; Casson, Porter and Wadeson, 2016).

A related point is that contracts can take different forms too. Parties are free to make contracts, but once they have made a contract they are constrained by its terms, and specifically by the obligations into which they have entered. The classic example concerns the employment contract, in which workers agree to be directed by their managers in return for payment of a wage. In the context of IB, licensees may be constrained in the prices they can charge for the products they sell, and in the export markets they can serve; franchisees may be constrained by the quality of service they must supply; while subcontractors may be constrained by the fact that they do not own the product they produce, as noted above (Buckley, 2009; 2011). This shows that it is not only ownership that confers control; contracts confer control as well.

There are also different options regarding a firm's headquarters and its location (Buckley, 2010). Headquarters functions such as finance, tax and operational control, though often co-located, can in fact be separated. These functions can, in principle, be located anywhere, although in practice they are likely to be located, for fairly obvious reasons, in large cities in relatively wealthy countries (see the special issue of Journal of Management Studies, 2017, 54(8)). Similar considerations apply to the location of R\&D.

With so many degrees of freedom in multinational operation, it is difficult to understand why many IB scholars still seem to believe that internalisation theory predicts that MNEs will be headquartered in developed Western countries, will carry out all their R\&D in their headquarters country, will only control what they own, and will therefore never control their licensees, franchisees or subcontractors. None of this is implied by internalisation theory (Casson and Wadeson, 2018).

Not only is there a wide range of forms that multinationality can take: there is also a wide range of factors that affect the form of multinationality that is chosen in any particular industry at a particular time. Many of the factors that determine multinationality were mentioned above; they influence both whether the firm is multinational and what specific form its multinationality takes. They range from 
cultural factors such as language barriers, through institutional factors, such as the strength of intellectual property rights, to purely physical factors such as international transport costs. These factors vary across countries, across industries, and over time. Diversity, not uniformity, is the hallmark of multinational operations.

IB scholars have repeatedly called for new theories to explain new patterns of multinationality that they have observed (see e.g. the contributors to Thite, Wilkinson and Budhwar, 2009). They have often failed to note that these new developments are directly driven by changes in the factors mentioned above. They are perfectly compatible with existing theory and, indeed, are often predicted by it.

Internalisation theory implies that multinational organisation is highly versatile. Multinational strategies adapt to changes in the international environment, so that when this environment changes, the organisational structures and the nationalities of leading firms will change as well (Casson, 2018). Cultural changes may reduce language barriers, thereby reducing the costs of international knowledge transfer and of centralised management control. Technological changes may reduce transport and communication costs, making exporting more attractive relative to foreign investment. Changes in global business strategies are not, therefore, autonomous events prompted by changes in business thinking, but intelligent responses to technological progress, falling transport costs, faster communications, greater international labour mobility, political integration through treaty organisations, and other factors identified by theory.

\section{A CULTURAL PERSPECTIVE ON IB THEORY}

The preceding remarks suggest that internalisation theory does not need to be extended because of any failure to explain emergent phenomena. The theory does what it sets out to do in a satisfactory way. But it could do more. For example, it could scale up its analysis from firm to industry, and examine oligopolistic market structures in global industries. In other words, it could do more to analyse the external environment of the firm. 
Extending the theory from the firm to the industry is not, in fact, so great a challenge as it sounds. The key principle of internalisation theory is essentially an economic principle, namely efficiency-seeking, and this principle also underlies the analysis of market structure. Just as the boundaries of the firm extend up to the margin where the benefit of further internalisation is just offset by the cost, so the number of firms in an oligopolistic global industry increases up to the point where a further entrant would just fail to break even, and so stays out because they could not make a profit.

Extending the theory by drilling down to the 'fine detail' of organisation and control within the firm is more problematic, however. Economic principles still apply, but their impact is moderated by sociological and psychological principles too. The importance of sociological and psychological factors reflects key differences between the external environment and the internal environment of the firm.

Firstly, the external environment of the firm is mainly competitive whilst the internal environment is co-operative too. In the external environment, for example, customers can readily switch between firms on the basis of price and product quality whereas within an organisation employees are usually 'locked in' to relationships with their colleagues. They cannot 'substitute' between the colleagues with whom they deal as easily as they can substitute between the products that they buy.

Secondly, interactions are more personal. Internal interactions are communication-intensive, whereas external interactions are usually not. External interactions between firm and customer may involve no more than displaying a price in a self-service store and collecting a credit card payment, whereas internal interactions may involve protracted negotiations with the same group of people before an outcome is achieved.

Thirdly, internal interactions tend to be multi-lateral rather than bilateral. External markets usually work through bilateral agreements, while organisations rely mainly on multilateral agreements effected by committees. Committees are required because a large amount of complex information must be synthesised in order to reach the correct decision; simple price comparisons are not sufficient 
for a correct decision. The outcome of committee decision-making processes is difficult to model and predict.

Fourthly, becoming an employee of a firm involves a greater personal commitment than becoming a customer. Employees may relocate to take a job, and must invest in getting to know their colleagues. Once 'locked in' they may begin to feel exploited; on the other hand, if they feel welcome they may develop loyalty to their employer. These attitudes complicate the way that their decisions are made.

Fifthly, tensions within a firm are managed and moderated by informal customs rather than formal legal processes. Because market transactions are so simple, enforcement is relatively simple to, and can be devolved to external legal institutions. Internal disputes are much more complicated; they may concern complex issues involving many people, as explained above, and can undermine the performance of an organisation unless they are resolved internally by consensual means.

Sixth, peer comparison is crucial where rewards within an organisation are concerned. Rewards are not purely material or pecuniary. Respect from colleagues and recognition from the employer are both important. Relative pay and hierarchical status may be more important than absolute pay; they are indicators of how much a person is valued by their organisation.

Finally, informal customs and the principles of peer-evaluation may different significantly between firms, and even between different parts of the same firm, e.g. between parent and subsidiary, or between one subsidiary and another. These differences are often summarised as 'cultural differences'; they may reflect the countries in which the organisation is located, and the dominant language, religion, or professional background of the employees (Andersson, Forsgren and Holm, 2007). In IB theory there has been a tendency to regard nationality as the key determinant of corporate culture, but in practice the situation is more nuanced; in high-tech firms that recruit globally, for example, shared professional allegiance may be more important than shared nationality in supporting internal cohesion.

This discussion demonstrates that any extension of internalisation theory into the micro-structure of organisations must take account of cultural issues. It is inappropriate to analyse the internal 
organisation of a firm by simply imposing on the subject economic ideas that have proved successful in analysing the external environment of the firm.

But this raises a further issue. Is the internal structure of the firm to be analysed using completely different concepts and techniques to those that are used to analysis the external environment, or is it possible to integrate the two? Indeed, what exactly would integration mean? The simplest answer to this question is that integration would need to be a two-way process.

Integration would involve applying cultural concepts to the external environment of the firm as well as the internal environment. An integrated theory would recognise that culture impacts on the diffusion of knowledge and the transfer of technology between countries. It would also recognise that it impacts on the formulation of global strategy: the cultural background of a CEO and their key advisers will frame their 'world view', and therefore influence their strategic decisions (Bouquet and Birkinshaw, 2011; Baer, Dirks and Nickerson, 2013). The economic domain of IB theory therefore needs to be opened up to cultural analysis.

Conversely, integration would involve applying economic concepts to analyse the internal organisation of the firm. Internalisation theory has always recognised that there are alternative organisational structures. At one extreme lies the centralised firm (the Williamson U-form), in which strategic decisions are taken at headquarters and the only role of subsidiary management is to implement the chosen strategy. At the other extreme is the divisionalised firm (the Williamson Mform) employing incentivised managers; headquarters and subsidiaries negotiate internal transfer prices for intermediate products, and managers receive pay based partly on the performance of their division and partly on their own performance within their division, measured relative to that of their peers (Williamson, 1975; 1985). In between these two extremes lie many alternative organisational forms (Verbeke and Yuan, 2005). Each form reflects a specific culture and operates under the influence of the corresponding cultural norms.

\section{DECISION-MAKING IN IB: CULTURAL AND ECONOMIC PERRSPECTIVES}

Obstacles to integrated theory 
An integrated theory sounds, in principle, like a really good idea. It could 'integrate' the IB profession, and halt the fragmentation into specialist silos that threatens so many academic disciplines. Empirical researchers would appreciate a convenient 'one-stop-shop' for theory. An integrated theory could become a 'flagship' for a revitalised field of study, and attract interest from cognate disciplines in business, management, and social science generally, as suggested at the outset.

But if it such a good idea, why has it not been developed already? The answer is that there are obstacles that need to be overcome (Felin, Foss and Ployhart, 2015). This paper argues that the major obstacle is the proliferation of different theories of decision-making in IB. The solution to this problem may not lie in standardisation on one specific decision-making theory, but the rather the identification of a suite of decision-making theories that are suitable for different levels of analysis. Each theory would be applicable to a particular type of decision. The integrated theory would explain why each type of theory was best adapted to each specific types of decision, as explained below.

\section{Degrees of rationality}

Decision-making is a fundamental component of all IB theory, and many controversies in IB ultimately stem from different views about how decisions are made. These differences are often expressed as a simple binary conflict between theories of rational action and theories of bounded rationality. This section of the paper proposes a more nuanced view. According to this view, different views of decision-making within IB are actually complementary rather than conflicting, because each addresses the weaknesses of the other. Within an integrated IB theory, the strengths of one approach would compensate for the weakness of the other, providing a versatile general theory.

There are many forms of bounded rationality. Indeed one of the key features of 'bounded rationality' is that it is defined, not by what it is, but by what it is not, namely that it is not purely rational. There are many ways in which a person can behave irrationally, and asserting that they are irrational is not a helpful way of predicting what they will do. Bounded rationality can mean anything from making a simple mistake to acting perpetually in an erratic and inconsistent way. 
Indeed, advocates of bounded rationality cannot even agree on what rationality means. In economic theory rationality is the ability to rank alternative outcomes in a logical and consistent way. It is sometimes equated, however, with acting on perfect information. This would imply that a person who rationally seeks out information must be irrational because of their limited information, whereas in fact they are rational because their search is conducted in a rational way. In other cases rationality is equated with pursuing self-interest. Self-interest however, is a moral choice that reflects indifference to the well-being of others. It is perfectly possible to pursue altruistic objectives is a rational way, which implies that self-interest cannot be the same thing as rationality.

There are different degrees of rationality that span the entire spectrum from perfect rationality based on perfect information through to bounded rationality based on very limited information (Buckley, Deviney and Louviere, 2010). All these forms of rationality can be theorised, but some types of rationality are more difficult to theorise than others. If the nature of decision-making is itself the subject of interest, as in psychology, then it is foolish to focus on the most simple form of rationality, namely perfect rationality. But if the focus is on business decisions such as location choice then it may be useful to focus on simple rationality in order to highlight the economic factors that are involved in the decision. In other words, it is appropriate to assume different types of rationality when analysing different types of problem.

It is also useful to assume different forms of rationality when examining the internal organisation of the firm and a firm's relation to its external environment. When focusing on the firm's environment, it is unhelpful to complicate the picture with sophisticated theories of decision-making, but when focusing on social relationships within the firm a simple theory of decision-making is a handicap. It is therefore most unfortunate that advocates of complex decision-making theories that work successfully 'inside' the firm denounce the use of simple decision theories 'outside' the firm, whilst advocates of simple theories used outside the firm deride the complex theories used inside the firm. Different theories of decision-making complement each other. Each is well adapted to analysing distinctive types of problem, all of which need to be addressed by IB theory. 
Different topics is IB theory therefore require different types of rationality in order to analyse them. The decisions of a solitary individual, such as a CEO, contemplating a complex environment, can most usefully be analysed using perfect rationality, so that the complexity of the environment is 'centre-stage'. On the other hand, a group of managers implementing a pre-determined headquarters strategy in a foreign subsidiary should be analysed differently, so that the more constrained rationality of their social interactions is featured instead. In general, the more complex the constraints that the environment imposes on decisions, the fewer constraints should be imposed on rationality, and conversely, the simpler the constraints imposed by the environment the more constraints can usefully be imposed on rationality. There is only so much complexity that a theory can handle; the more complex the environment, the simpler the theory of decision-making needs to be.

The nature of a decision

Decision-making theories vary from the very simple to the highly complex. Simple behavioural theory postulates a one-to-one connection between a stimulus and a response; It portrays decisionmaking as a knee-jerk reaction which does not engage the brain. Decision-making may also be portrayed as inertial, involving the use of habitual routines (Winter, 2013). By contrast, simple rational action, almost by definition, involves the brain. Choice between alternatives is key. The 'choice set' specifies the number of options that need to be evaluated; the greater the number of discrete alternatives, the more complicated the decision (Simon, 1961, 1967, 1982).

To compare alternatives some criterion is required. The valuation of alternative options will depend on the environment in which the decision is taken. Theory will suggest which factors are relevant to valuation; the more factors there are, the more evidence the decision-maker needs to collect, and the greater the cost of taking a decision.

Simplifying a decision can save considerable cost. Simplification strategies include reducing the number of options to be considered, using a simple criterion, ignoring various factors, and only collecting the most accessible information (Cyert and March, 1963; Kostova and Roth, 2012). 
Economising on decision costs can be perfectly rational as a strategy, even though it may lead, on average, to a worse decision (see below).

Some people may have better judgement than others, and therefore achieve, on average, better outcomes for a given cost. A person's judgement may reflect both personality and culture. Culture influences the basic assumptions they make when simplifying a decision. Personality may influence the sources of information they prefer (e.g. family or friends; documents or databases) and how drastically they simplify their decision. Decisions are often made using indicators or symptoms of underlying factors that cannot be observed. Good judgement involves choosing the most appropriate indicators in each specific situation (Casson, 2003).

People with superior judgment may specialise in taking decisions on behalf of others. People who lack decision-making skills may delegate business decisions to people whom they believe have better skills. This is particularly important with complex decisions. For example, one reason why shareholders in an MNE delegate strategic decisions to the CEO is because they believe the CEO has better judgement in complex business matters than they have themselves.

Statics and dynamics

There is an important distinction between static and dynamic theories of decision-making. Static decision-making relates to a single period of time, while dynamic decision-making relates to a sequence of periods (Dixit and Pindyck, 1994). In dynamic theories of decision-making the number of periods may be finite or infinite. In static theories the time elapsing between successive events is so small as to be negligible. In static internalisation theory, for example, a CEO begins by observing the market they plan to enter, they then decide their mode of market entry, and finally they implement their chosen strategy; all this takes place within a single period.

A key issue in dynamic theorising is whether the decision-maker is fully aware of the evolving situation in which they operate. Are they aware that what they decide in the first period may have legacy effects in subsequent periods? In particular, do they take 'real options' into account? Legacy effects can be direct or indirect, e.g. investing in durable assets not only generates resources for future 
periods ( a direct effect), but also limits options for future investment by committing resources now that could have been used later instead (an indirect effect). Direct effects are easy to take account of in dynamic theory, but indirect effects are not.

Agents who fail to take account of indirect legacy effects may be described as myopic. They may recognise that decisions taken in the past frame the options available to them in the current period, but fail to recognise that decisions taken in the current period frame the decisions they can take in the future. Decision-making by myopic individuals can be modelled as a sequence of essentially static decisions. The options available in the current period are perceived as a legacy of decisions made in previous periods, but no account is taken of future options when taking current decisions.

\section{Risk and uncertainty}

The availability of information is another factor affecting the complexity of decision-taking. Does the decision-maker actually know that state of the environment at the time they take their decision? Lack of information generates risk and uncertainty (Hutzschenreuter, Kleindienst, Grone and Verbeke, 2014). In internalisation theory, for example, it is often assumed that the decision-maker knows the relevant characteristics of each market before they enter them, but if they have not entered them then how can they truly know the state of the market? A full account of the market entry decisions would take account of how the information required to take the market entry decision is obtained.

Radical uncertainty arises when the decision-maker does not even know what it is that they are uncertain about. For example, a firm entering a foreign market may not understand that the government is corrupt because they have no previous experience of government corruption and are unaware that it is even an issue. Uncertainty is less radical when the decision-maker knows what is possible but does not know the probability attached to each possibility. In these circumstances the decision-maker may associate a subjective probability with each possibility, based on their judgement or intuition, but without any conviction that these probabilities are correct. In some cases, however, precedents for the decision may provide information from which a risk-assessment can be generated. 
In this case the relative frequencies of past occurrences can be used to generate the probability values associated with the various possibilities (Knight, 1921; Foss and Pedersen, 2014).

Searching for information

Search can also be used to address uncertainty. The decision maker pro-actively seeks out information to inform decisions (Hirshleifer, 1989; Hirshleifer and Riley, 1992). Search introduces a sequential element into the decision-making process. The decision-maker first decides whether to seek out information, and if so when to stop. Search does not eliminate uncertainty, because when a search commences the searcher does not know what they will find; but once the search has been completed the ensuing decision will be less uncertain than it was before. To inform their search decisions the decision-maker needs to know the costs of the search process, the various possibilities they might discover, and the prior probability of each. Once the search has been completed, these prior probabilities are replaced by posterior probabilities which tend to be more accurate. Some posterior probabilities may approximate to certainty, even if they do not point to a single outcome.

Experience can also be used to address uncertainty. An experienced decision-maker can search through their personal memory bank to identify precedents for their situation. Precedents may by identified by some analogy with the present situation; they do not have to replicate it exactly (Buckley, Clegg, Chen and Voss, 2016). Analogies can, however, can be misleading, as crucial difference between superficially similar situations may be overlooked. Reliance on misleading analogies can make decision-makers over-confident about the outcomes of the decisions that they make.

Dynamics of learning

Learning is extremely difficult to theorise. Despite recent advances in artificial intelligence, the subject remains poorly understood. Yet learning is core to IB theory, and especially to the internationalisation process (Forsgren and Johanson, 1992; Johanson and Vahlne, 2009). There are three main approaches to learning that are relevant to IB, and all merit further development (Kogut and Zander, 1996). 
The first is Bayesian learning, in which prior probabilities are revised and updated in response to new information. The principles are sound and straightforward, but implementation is complex (Neal, 1996).

The second is pattern recognition, where new events are tentatively linked to other changes that occurred at about the same time. Pattern recognition is typical of computerised learning algorithms based on correlation analysis. These can be very successful where similar events routinely recur, but not so good when novel events require investigation.

The third approach is behavioural. Good outcomes are attributed to good decisions which are then repeated with greater frequency, while bad events are attributed to bad decisions which are then repeated with lower frequency. The behavioural approach is the simplest of the three, but only because it is the least sophisticated. In practice, the attribution of cause to effect may be superficial and emotional, rather than careful and considered. As a result, the behavioural approach tends to understate the element of luck in any outcome, and overstate the importance of the decision; this leads to good decision-making being discredited because of bad luck and, conversely, bad decision-making being reinforced by good luck.

Theories of decision-making: a summary

The discussion is summarised in Table 1. Perfect information theory is so simple in comparison to others that it is used in both static and dynamic theory. The use of perfect information in static economic theory demonstrates the major insights that can be achieved by using simple assumptions to bring clarity to complex problems. Internalisation theory is just one instance of numerous cases of this kind. Despite being counter-intuitive, perfect information is also used in dynamic theories to illustrate issues relating to investment and capital accumulation.

Theories of rational decision-making under uncertainty are used to analyse business and financial risks, including the risks of business failure, while theories of rational search are used to analyse information gathering through global scanning by CEOs and their headquarters staff. Theories of learning have so far received little attention in mainstream IB theory, however. Part of the 
explanation is that dynamics has remained an under-developed area of IB theory. Part of the reason for that is that many IB issues are quite complicated even without their dynamics, so that adding dynamics is very challenging. Dynamics is most effective in fields of IB where the fundamentals are relatively simple.

\section{TABLE 1 HERE}

\section{BUSINESS ETHICS AND PROFIT MAXIMISATION}

Criteria for the best decision

Having examined the process of decision-making in some depth, it is appropriate to consider other issues relating to the choice of the decision criterion. Most economic analysis of corporate decisionmaking assumes profit-maximisation, but many IB scholars reject this view. From a methodological perspective, two issues need to be considered. The first is whether the CEOs of firms maximise anything at all, and the second is why, if they do, they would wish to maximise profit (Scott, 1981).

Most firms are set up by their founders with some sort of objective in mind, and that objective can usually be expressed in terms of something that can be maximised. What they maximise does not have to be merely the profit they derive from the business, however. It could be their personal reputation, or the wealth they leave behind when they die. The founder of a family business may wish to provide employment for family members; the founder of a consumer co-operative may wish to sell affordable products to customers; and the founder of a workers' co-operative may wish to pay high wages to their employees. In all of these cases the existence of a well-defined objective means that the decision-maker is seeking to maximise the value of some target variable (Casson, 1991).

\section{Multiple objectives}

A decision-maker could have multiple objectives. This complicates the analysis, but does not undermine it. There are two main possibilities. 
The first is that the decision-maker attempts to maximise a weighted average of two or more target variables, e.g. profit and reputation. While the existence of multiple objectives seems quite plausible, it raises the question of how the relevant weights are determined. Without knowledge of the weights that a decision-maker is using it is difficult to predict the decision they will make.

The second approach is to assume that the decision-maker maximises the value of one target subject to a constraint that some other target must be met. For example, an ethical CEO might wish to maximise growth subject to the constraint that workers receive a minimum wage. Higher growth could be achieved by reducing wages and cutting prices to gain market share, but this growth is sacrificed in the interests of social justice.

An important constraint on any firm is survival; it is difficult for a firm to survive if it makes sustained losses. Survival also applies to the CEO. If the firm's equity falls into the hands of institutional investors, these investors may demand generous dividends, backed by a high rate of return. This can only be sustained through high profits, and so a profit constraint becomes key to the CEO's survival. If the equity is held by speculators, then a share-price constraint may prevail instead. In general, any pursuit of ethical objectives will be constrained by some sort of financial performance criterion; even purely charitable organisations have to break even in the long run.

Profit-maximisation, therefore, is simply the limiting case of a general requirement, namely that a minimal level of financial performance is required for any large organisation to survive. Under difficult conditions, e.g. in a highly competitive industry with excess capacity, survival may become so demanding that it dominates all other considerations, and profit-maximisation emerges as the sole objective.

The ethics of profit-maximisation

It is sometimes suggested that profit-maximisation is itself an ethical objective. CEOs, it is said, are stewards of shareholder's interests and are bound to act as they desire. Many shareholders, however, may not wish to hold shares in an unethical business, which means that they desire any business in which they invest to behave in an ethical way. From this perspective, the shareholders can require the 
CEO to maximise profit subject to an ethical constraint, instead of maximising an ethical objective subject to a profit constraint, as above.

If shareholder interests are not dominant, then management interests may become dominant instead. A CEO may seek to make their firm as large as possible in order to increase their executive power and their personal reputation. They may have ethical concerns as well. They may, for example, set a minimum wage for the benefit of their employees and their families. But even if shareholders are passive, there is still a constraint: the firm must pay interest to banks and bondholders. In this case firm growth is maximised subject to a financial constraint and a wage constraint (Penrose, 1959).

However complex the motives of corporate decision-makers, therefore, there is always good reason to believe that their objectives involve the maximisation of some target variable subject to one or more constraints. The assumption of profit maximisation is a plausible way of radically simplifying the objectives of a CEO. Many alternatives have been discussed in the literature, especially the maximisation of sales revenue, revenue growth, and share price. In most of these cases a high level of profit is essential to sustain high performance. Thus while alternative objectives nuance the pursuit of profit, they do not remove the profit motive altogether.

\section{THE SOCIAL BASIS OF DECISION-MAKING}

Delegation of decisions: autocracy or consultation

A decision-maker can pool the experiences of other people through consultation. It may be useful to consult, not only those with experience, but also those who will be involved in the implementation of a decision. People may be consulted individually or collectively, and informally or formally. Individual consultation is often informal (e.g. a confidential chat) while collective consultation may be formal (e.g. in committee). It is also possible, however, to meet formally one-to-one (e.g. an interview) or informally as a group (e.g. at dinner).

The benefit of consultation is that diverse opinions reveal the full complexity of the situation. Consultation may also win 'buy in', creating a consensus to which everyone is committed. The 
disadvantage is that irreconcilable opinions may be voiced, polarising participants into opposing groups.

Peer-to-peer decision-making

Peer-to-peer decision-making occurs when two or more decision-makers control their own resources. The decisions of each decision-maker impact the outcome achieved by the other. In a global oligopoly, for example, CEOs have to take account of other CEO's decisions. This applies both whether the CEOs are joint-venture partners or market-share maximising rivals, or both.

The outcome of peer-to-peer decision often depends on the sequence in which people communicate with each other and the sequence in which they make their moves. In many instances neither sequence is specified in advance. This makes modelling peer-to-peer decision-making extremely complex.

Expectations play a crucial role in peer-to-peer decision-making. Each peer has an expectation of how others will act in response to their own decisions. Communication can play an important role in shifting expectations. Agreement on a contract is most likely once expectation are aligned; e.g. the buyer does not believe the seller will accept less and the seller does not believe that the buyer will pay more.

Alternative options also play a crucial role in aligning expectations. Consider a two-stage production process where the CEO of a downstream firm is negotiating with the CEO of an upstream firm to buy some intermediate product. The buyer will try to persuade the seller that another seller has offered them a lower price while the seller will try to persuade the buyer that another buyer has offered them a higher price. In a competitive market both buyer and seller have a wide range of options, giving credibility to these claims, and helping to drive the buyer and seller towards an equilibrium price. If neither buyer nor seller have alternative options, however, and both are aware of this, then they are locked into a 'zero-sum' game. In this context internalisation of the intermediate product market through merger or acquisition offers a convenient solution to protracted bargaining. In terms of 
internalisation theory, bilateral monopoly increases transaction costs by impeding negotiation and thereby favours vertical integration.

Another major area of peer-to-peer decision-making in IB is innovation rivalry. Innovation typically involves large sunk costs that cannot be recovered if it fails. The value of an innovation depends crucially on monopoly of exploitation, because competition to exploit an innovation will drive down product price towards the marginal cost of production and innovators will fail to cover the sunk costs of R\&D. Under these conditions the sequencing of decisions is crucial.

If two firms plan to innovate competing products, and they make their moves sequentially, then first mover advantage is likely to prevail. Single firm innovation is profitable because it yields monopoly, but two-firm innovation may result in losses for both. Each firm's decision strategy is therefore 'I will innovate if and only if the other does not'. Under these conditions, whoever innovates first takes the whole of the market and makes a monopoly profit, because once they have innovated their rival will stay out. Sequence is everything, as the 'first mover wins' and the 'winner takes all'.

This is not the only scenario, however. If the second mover can imitate the first mover's innovation, they can avoid sunk costs and get a 'free ride'. Under these conditions, 'After you!' may be the dominant strategy for both players. Each wants to be second, and the other to be first. But if they both wait for each other then the opportunity may be lost. Communication may be useful in securing innovation. The firms may form a cartel in which the first-mover's costs are reimbursed out of the profits they jointly make. If a cartel agreement is difficult to enforce; they may merge instead; in this case internalisation, once again, resolves a strategic issue in peer-to-peer communication .

These are both very simple cases. With several firms, each with several options, there are many possible outcomes to evaluate. Peer-to-peer decision-making is therefore a major challenge for IB theory. But it is a major challenge for other subjects too, including economics. A theory that modelled peer-to-peer decision-making in a general context and took account of all the possibilities would be formidably complicated. It would probably be so complicated that it would be impossible to understand. 
A fundamental problem with decision-making theory, therefore, is that scholars themselves are boundedly rational, and can only cope with so much complexity. Simple theories are a necessity. A theory can be simple either because the environment is simple or because decision-taking is modelled in a simple way. When the environment is complex, as it is outside an organisation, the decisionmaking process must be simple if it is to be intelligible. If the environment is simple, however, as it is (relatively speaking) inside an organisation, then the decision-making process can be complex. Social realism may work inside the organisation, but economic rationality normally needs to prevail outside.

IB is distinctive in having many different contexts in which complex peer-to-peer communication is a crucial issue. It is therefore an excellent field in which pioneer new ideas about how to simplify decision-making when analysing complex situations. Indeed, several of the papers in this special issue engage, directly or indirectly, with this fundamental issue.

\section{THE CONTRIBUTION OF THIS SPECIAL ISSUE}

The analysis of decision-making presented above has drawn, not only on our own reflections, but on the contents of the special issue papers. In this section each of the papers is considered in turn, with the aim of identifying commonalities and relating them to our discussion.

Elia, Larsen and Piscitello (paper 5) take a behavioural approach to international entry mode decisionmaking. Its cognitive perspective is contrasted with discrete stand-alone entry mode decisions. Past decisions, particularly underperforming past ventures, exercise an influence on future decisions leading to "entry mode deviation". This is compounded by an "availability bias" where recall of past decisions influences future decisions. This paper highlights the issue of far-sighted decision-making versus myopia in MNEs and has a particular take on the dynamics of learning, suggesting particular biases in both the search for information and the boundaries of rationality.

The nature of decision making in networks, particularly within business groups, is explored by Gaur, Pattnaik, Lee and Singh (paper 3). This paper has the virtue of linking the organisational structure of the firm, its network links and the external environment of the host countries in which the MNE operates. Inter-affiliate trade is a key element linking these aspects of the firm. The internalisation or 
externalisation of these flows is linked to both the ethnocentrism of top management and the strengths (or weaknesses) of the institutional environment in which the MNE operates. This study provides insights into the social bases of decision making and the influence of uncertainty arising from weak institutional arrangements in host countries. It then builds a picture of the pressures on decisionmakers to coalesce into business groups rather than operate as stand-alone enterprises.

The central concern of paper 4 by Grogaard, Rygh and Benito is decision-making in foreign entry strategies. It focuses on state-owned enterprises, and examines the influence on their decision-making of their governance characteristics; these affect risk preferences and reflect non-economic goals. The authors construct a special application of internalisation theory which accounts for the institutional environment in the source country of the SOEs. This paper develops some of the points made in our discussion of rationality above; it serves to highlight the importance of governance in conveying important decision-making signals to managers. Such signals may affect risk preferences and, in the case of SOEs, may be "politically loaded".

Wang and Li (paper 8) examines the impact of public disclosure of corporate irresponsibility on the decision-making of MNEs. This paper contextualises the conflict between ethics and profitmaximisation in the specific context of media coverage of MNEs' irresponsibility. These events cause a reappraisal of decision-making and governance within MNEs, providing a natural experiment involving the shock of public disclosure of irresponsibility on the MNE. The standard response is that the MNE seeks greater control over information but distances itself from the source of the problem by reducing its ownership exposure. This paper illustrates the importance of the social basis of decisionmaking, and provides a test case of the impact of a shock in decision-making structures in MNEs.

The relationship between MNEs or "focal firms" or "orchestrating firms" in global value chains (GVCs) is a topic of great current interest. Strange and Humphrey (paper 6) examine control mechanisms in GVCs and link these mechanisms to power asymmetries between focal firms and partners, and to the degree of codifiability of the information exchanged through their relationship. Decision-making within the MNE, and between the MNE and its network partners, is influenced by the degree of monopoly or monopsony of the entities concerned. The nature of the decisions taken 
also reflect the availability of information and its routine or surprising content. The degree of control given to the orchestrating firm in a formal contract is not to be underestimated. Indeed it is arguable that the formidable array of orchestrating controls, monitoring, dictat and specification clauses in a modern outsourcing contract actually exceeds the control exercised over a nominal subsidiary. Subsidiaries are often given a mandate to innovate in a prescribed area by the parent whereas outsourced firms are forbidden to go beyond the contract in any way that the principal can enforce.

Benito, Petersen and Welch (paper 7) criticise Strange and Humphrey for over-simplifying the role of contracts, arguing that a contract can act as a useful point of reference in an essentially trustful relationship. This accords with the point made earlier, that the distinction between ownership and contract is often excessively binary in the literature. Contracts can take a variety of forms, and the crucial issue for coordination is often not one of ownership versus contract but rather the specific form that that a contract takes.

Dhanaraj and Banaliva (paper 1) show that digitalisation affects transferability, bundling and appropriability of technology and assets and affects decision-making in price setting and in the governance systems of modern MNEs. Because the firm operates less as a stand-alone entity and more as a network, decision-making has to undergo profound changes to reflect the dynamics of learning from network partners and the search for information within and beyond the network. There is an emphasis on peer-to-peer decision-making in situations where delegation requires consultation rather than autocratic decision making. We agree with Hennart (paper 2), however, that these points can be made perfectly well within the existing framework of internalisation theory. Digitalisation is just the latest radical innovation in a sequence of innovations that have transformed the world of business since the end of the nineteenth century. Internalisation is a general theory of multinational business, and not a specific theory of late twentieth-century business. As indicated earlier, the theory does not need to be re-formulated every time some radical technological change occurs.

Lopes, Jones and Casson (paper 9) examine decision-making processes in knowledge-based MNEs from a historical perspective and show that the process is much less hierarchical and much more cooperative than previously conceived. The authors suggest that increases in uncertainty in the present 
global economy will induce more flexible organizational forms and more innovative and unconventional decision making.

Collectively, the papers in this special issue advance our knowledge on decision-making in the modern MNE. A popular conception of the modern MNE involves a network orchestrated by the focal firm that manages the ownership of product or service as it moves from conception to the customer. Subcontractors own assets to process the product or service. Ownership gives a residual class of claims on revenue appropriation. Contracts specify contingencies in order to hedge against uncertainty; they reflect the focal firm's intention to monitor quality, optimise the performance of the overall supply chain and maximise overall returns across all its activities. Decision-making has a crucial role in confronting the complexities and uncertainties inherent in the value chain. The papers all make a serious attempt to analyse diverse aspects of these complex issues and add to our understanding of decision-making under uncertainty in the modern MNE.

\section{CONCLUSION}

IB theory achieved success in the 1970s and 1980s through the application of simple rational action models to IB issues. The market entry decisions of MNEs were derived from profit maximisation subject to the transactions costs of alternative contractual arrangements. Decision-making issues were not ignored, but were subsumed in the category of transaction costs. It later became the practice to impute transactions costs entirely to imperfect property rights, but the costs of negotiating contracts have always been an important part of the theory.

Once the basic rationale of multinational business had been established, it was natural for IB to progress to the detailed consideration of organisational structure and headquarters-subsidiary relations (Westney, 1993). As indicated above, simple rational action modelling has serious limitations in this domain. In retrospect, it was perfectly natural for other concepts of rationality to be invoked to analyse these organisational issues. The mistake was to assume that both types of rationality could not co-exist together. Introducing perfect information into organisational structure assumes away key issues, but equally, introducing bounded rationality into market entry decisions is liable to complicate 
an already complex issue. It is not impossible to do, but it requires considerable subtlety to do it well, as explained above.

Using multiple concepts of rationality with a single body of theory can cause confusion, however. It is important to have a coherent view of which form of rationality provides the most appropriate tool for analysing particular fields of IB. The discussion above suggests that rational action will always have an important role in analysing the place of multinational business within the global economy. Where oligopolistic markets are concerned, peer-to-peer modelling will be required, and so sequential structures may be needed to simplify the analysis of rivalry and partnership in innovation. Within the organisation, where social interaction is crucial to high-trust communication, decision models will be complex, reflecting the influence of cultural factors. Managing the interface between different elements of IB theory will be challenging, but with respect and goodwill within the IB community it can surely be done. 


\section{REFERENCES}

Andersson, U., Forsgren, M., \& Holm, U. (2007). Balancing subsidiary influence in the federative MNC: A business network view. Journal of International Business Studies, 38(5), 802-818.

Asmussen, C.G,, Larsen, M.M., and Pedersen, T. (2016) Organizational adaptation in offshoring: The relative performance of home- and -host country learning strategies. Organizational Science, 27(4), 911-928.

Baer, M., Dirks, K. T., \& Nickerson, J. A. (2013). Microfoundations of strategic problem formulation. Strategic Management Journal, 34(2), 197-214.

Bouquet, C., \& Birkinshaw, J. (2011). How global strategies emerge: An attention perspective. Global Strategy Journal, 1(3-4), 243-262.

Buckley, P. J. (2009). The impact of the global factory on economic development. Journal of World Business, 44(2), 131-143.

Buckley, P. J. (2010). The role of headquarters in the global factory. In U. Andersson \& U. Holm (Eds.), Managing the contemporary multinational-The role of headquarters (pp. 60-84). Cheltenham, England: Edward Elgar

Buckley, P. J. (2011). International integration and coordination in the global factory. Management International Review, 51(2), 269-283.

Buckley, P. J., \& Casson, M. (1976). The future of the multinational enterprise. Basingstoke and London, England: Macmillan.

Buckley, P. J. and Casson, M. (2019) The internationalization theory of the multinational enterprise: past, present and future. British Journal of Management. Early view, ISSN 1467-8551

Buckley, P. J., Chen, L., Clegg, L. J., \& Voss, H. (2016). Experience and FDI risk-taking: A microfoundational reconceptualization. Journal of International Management, 22(2), 131-146. 
Buckley, P. J., Devinney, T. M., \& Louviere, J. J. (2007). Do managers behave the way theory suggests? A choice-theoretic examination of foreign direct investment location decision-making. Journal of International Business Studies, 38(7), 1069-1094.

Cantwell J.A. (ed.) International Business and the Eclectic Paradigm: Developing the OLI Framework, London: Routledge.

Casson, M.C. (1991) Economics of Business Culture: Game Theory, Transactions Costs and Economic Performance, Oxford: Oxford University Press

Casson, M.C.(1995) Information and Organization, Oxford: Oxford University Press

Casson, M.C. (2003) The Entrepreneur: An Economic Theory, Cheltenham, England: Edward Elgar

Casson, M. (2014) Coase and international business: the origin and development of internalisation theory. Managerial and Decision Economics, 36 (1). pp. 55-66.

Casson, M.C. (2016) The Theory of International Business: Economic Models and Methods, Basingstoke, England: Palgrave Macmillan

Casson, M., Porter, L. and Wadeson, N. (2016) Internalization theory: an unfinished agenda. International Business Review, 25 (6). pp. 1223-1234.

Casson, M. (2018) The theory of international business: the role of economic models. Management International Review, 58 (3). pp. 363-387.

Casson, M. and Wadeson, N. (2018) Emerging market multinationals and internalisation theory. International Business Review, 27 (6). pp. 1150-1160

Coase, R. H. (1937). The nature of the firm. Economica, 4(16), 386-405.

Cyert, R. M., \& March, J. G. (1963). A Behavioral theory of the firm. Englewood Cliffs, NJ: Prentice Hall. 
Dixit, A.K. and Pindyck, R.S. (1994) Investment under Uncertainty, Princeton, NJ: Princeton University Press

Eden , L. (2003) A critical reflection and some conclusions on OLI, in J.A.Cantwell (ed.)

International Business and the Eclectic Paradigm: Developing the OLI Framework, London:

Routledge, pp.277-297.

Egelhoff, W. G. (1988). Organizing the multinational enterprise-an information-processing perspective. Cambridge, MA: Ballinger.

Egelhoff, W. G. (1993). Information-processing theory and the multinational corporation. In S.

Ghoshal \& E. Westney (Eds.), Organization theory and the multinational corporation (pp. 182-210). New York: St. Martin's Press.

Felin, T., Foss, N. J., \& Ployhart, R. E. (2015). The microfoundations movement in strategy and organization theory. The Academy of Management Annals, 9(1), 575-632.

Forsgren, M., \& Johanson, J. (1992). Managing internationalization in business networks. In M. Forsgren \& J. Johanson (Eds.), Managing networks in international business (pp. 1-16). Philadelphia, PA: Gordon \& Breach

Foss, N. J., \& Pedersen, T. (2014). Microfoundations in strategy research. Strategic Management Journal, 37, E22-E34. https://doi.org/10.1002/smj.2362

Hennart, J. F. (1982). A theory of multinational enterprise. Ann Arbor, MI: University of Michigan Press.

Hirshleifer, J. (1989) Time, Uncertainty and Information, Oxford: Blackwell

Hirshleifer, J. and J.G.Riley (1992) The Analytics of Uncertainty and Information, Cambridge: Cambridge University Press

Hutzschenreuter, T., Kleindienst, I., Gröne, F., \& Verbeke, A. (2014). Corporate strategic responses to foreign entry: Insights from prospect theory. Multinational Business Review, 22(3), 294-323. 
Hymer, S. H. (1976). The international operations of national firms: A study of direct foreign investment. Cambridge, MA: MIT Press.

Johanson, J., \& Vahlne, J. E. (2009). The Uppsala internationalization process model revisited: From liability of foreignness to liability of outsidership. Journal of International Business Studies, 40(9), $1411-1431$.

Knight, F.H. (1921) Risk uncertainty and profit, Boston: Houghton Mifflin

Kogut, B., \& Zander, U. (1996). What firms do? Coordination, identity, and learning. Organization Science, 7(5), 502-518.

Kostova, T., \& Roth, K. (2002). Adoption of an organizational practice by subsidiaries of multinational corporations: Institutional and relational effects. Academy of Management Journal, 45(1), 215-233.

Neal, R.M. (1996) Bayesian learning for neural networks, New York: Springer

Penrose, E. (1959). The theory of the growth of the firm. New York, NY: Wiley.

Rugman, A. M., \& Verbeke, A. (2008). Internalization theory and its impact on the field of international business. In J. J. Boddewyn (Ed.), International business scholarship: AIB fellows on the first 50 years and beyond (pp. 155-174). Bingley, England: Emerald Group Limited.

Scott, W. R. (1981). Organizations: Rational, natural, and open systems. Englewood Cliffs, NJ:

Prentice Hall.

Simon, H. A. (1961). Administrative behaviour (2nd ed.). New York, NY: Macmillan.

Simon, H.A. (1967) Models of man, New York: John Wiley

Simon, H. A. (1982). Models of bounded rationality and other topics in economics. Cambridge, MA: MIT Press.

Stopford, J. M., \& Wells, L. T. (1972). Managing the multinational enterprise. New York, NY: Basic Books. 
Thite, M., Wilkinson, A. and Budhwar, T. (eds.) (2016) Emerging-Market Multinationals: Strategic Players in a Multipolar World. Oxford: Oxford University Press

Verbeke, A., \& Yuan, W. (2005). Subsidiary autonomous activities in multinational enterprises: A transaction cost perspective. Management International Review, 45(2), 31-52.

Westney, E. (1993). Institutionalization theory and the multinational corporation. In S. Ghoshal \& E. Westney (Eds.), Organization theory and the multinational corporation (pp. 53-76). New York, NY: St. Martin's Press.

Williamson, O. E. (1975). Markets and hierarchies. New York, NY: Simon and Schuster.

Williamson, O. E. (1985). The economic institutions of capitalism: Firms, markets, Relational Contracting. New York, NY: Free Press.

Winter, S. G. (2013). Habit, deliberation, and action: Strengthening the microfoundations of routines and capabilities. The Academy of Management Perspectives, 27(2), 120-137. 
Table 1 Types of individual decision-making most commonly used in static and dynamic theories

\begin{tabular}{|l|l|l|}
\hline Method of & Static theory & Dynamic theory \\
decision-making & & Yes \\
\hline Rational: Perfect information & Yes & \\
\hline Rational: Uncertainty & Yes & \\
\hline Rational: Search & Yes & Yes \\
\hline Learning: Bayesian & & Yes \\
\hline Learning: Artificial & & Yes \\
\hline intelligence & & \\
\hline Learning: Behavioural & & \\
\hline
\end{tabular}

